\title{
Velocity and thermal field thermography for thermoplastic polymers extrusion
}

\author{
by G. Cuccurullo ${ }^{4}$ and L. Di Maio ${ }^{2}$ \\ ${ }^{1}$ Department of Mechanical Engineering, University of Salemo, Fisciano (SA), Italy ; ${ }^{2}$ Department of \\ Chemical and Food Engineering, - University of Salemo, Fisciano (SA), Italy
}

\begin{abstract}
Cast film production is a common operation in polymer processing: different models have been developed to predict the film behaviour at the die exit. The model presented in this paper takes in to account both the inertia forces and the gravity in the momentum equation; this last is coupled with the energy equation by considering temperature dependent properties. Analytical results, obtained by numerical integration using a shooting method, are compared with experimental ones obtained on a pilot plant: extrusions on thermoplastic polymers, namely PET and PP, at different die to chill roll distances and at different flow conditions (mass rate, drawing and cooling), were performed. The film thermal response, in the region between die exit to chill roll, was detected by means of an AGEMA 870 IR system. First experimental tests showed quite different behaviors for PET and PP, probably due to different crystallization kinetics. Analytical results are presented and compared with experimental data.
\end{abstract}

\section{Introduction}

In the polymer processing industry most applications involve extrusion in the molten state: extruded polymers undergo a continuous process, acquiring the shape of the die opening. In the field of film extrusion, the quality of the final product strongly depends on the operative process conditions, affecting mechanical and surface properties; one of the most critical operating parameters is the film temperature $[1,2]$.

In this work attention is focused on cast film production: the polymer, extruded through a slit die, is slightly stretched in the machine direction in air and then cooled on a chill roll. The route in air of the material from the die to the chill roll is essential in determining the final film properties, in fact strong variations in width, thickness and temperature take place in a short time, while the material becomes solid. In spite of that, only few papers have been devoted to consider the coupled velocity and temperature fields [3].

The objective of this study is to determine the thermal-fluid-dynamics behaviour of the cast film extrudate, and to validate the model predictions with the experimental data obtained by means of I.R. Thermography. The basic equations, i.e. the mass, momentum and energy balance, and two additional ones, coming from force balance at film surface, lead to a set of first order non linear differential equations with two point boundary conditions $[4,5,6]$; the problem is solved numerically by a fourth order Runge Kutta scheme, making use of a shooting method. Film casting extrusions were performed on thermoplastic polymers, namely polyethylenetherephtalate (PET) and polypropylene (PP), on a pilot plant in order to evaluate the materials behaviour at different conditions of mass rate, drawing, cooling and die exit to chill roll distance. The two polymers were chosen with the aim of studying the response of different rheological properties and crystallization kinetics. Surface temperature maps of the extruded film were obtained by making use of I.R. thermography for each testing condition. The results are presented and discussed for different conditions of mass rate, drawing, cooling and take up distance. 


\section{Basic equations}

The sketch of the extrusion process is shown in fig. 1. The film is assumed to be thin and the cross section to exhibit uniform thickness; the edge effect for velocity and temperature field are neglected. In the core region of the film, i.e. the region close to the centerline, experimental evidence shows that the longitudinal velocity and temperature vary slightly along the width: thus they are assumed to depend only on the longitudinal spatial variable.

The film is cooled by convective-radiative heat transfer on both faces to an environment at constant temperature: classical correlations for a flat plate are used to describe locally natural and forced convection.

The rheological behaviour of the polymers under sfudy is well described by the Ostwald-De Waele model (power law); because of low shear rates at die exit such as in film casting, the power law recovers the Newtonian behaviour:

$$
\sigma_{\mathrm{ij}}=-\mathrm{p} \delta_{\mathrm{ij}}+2 \mu \varepsilon_{\mathrm{i}, \mathrm{j}}
$$

where $\mu$ is the shear viscosity (strongly temperature dependent), $\varepsilon_{i, j}$ the strain tensor and $p$ the hydrostatic pressure.

The temperature dependence of polymer viscosity can be modelled according to Arrhenius law, while the density and heat capacity vary linearly with temperature (see Appendix).

The polymer is thermally modelled as a Fourier fluid; due to its low thermal conductivity and high viscosity, it exhibits high Peclet numbers: transverse and axial heat conduction are neglected with respect to the convected term in the energy balance equation.

In the momentum equation the air drag force and interfacial tension are neglected.

The basic dimensionless equations are obtained from the mass, momentum and energy balance; two additional equations are related to force balance at film surface $[7,8]$ :

$$
\begin{aligned}
& \rho^{*} s b u=1 \\
& d f / d x=d u / d x-\left(1 / F r^{2}\right) \rho^{*} s b \\
& d t / d x=-S t /\left(\rho^{*} c_{p}^{*} u s\right)\left\{-h^{*} t+N\left[\left(1+\Delta T / T_{\infty}\right)^{4}-1\right]\right\} \\
& d u / d x=-[u(d b / d x) /(2 b)]\left[8-(d b / d x)^{2}\right] /\left[2-(d b / d x)^{2}\right] \\
& d b / d x=-G f\left[2-(d b / d x)^{2}\right] /\left(\mu^{*} u s\right)
\end{aligned}
$$

where the dimensionless variables are: $x=X / B_{0}$, the longitudinal spatial coordinate; $s=S / S_{0}$, the thickness; $b=B / B_{0}$, the width; $u=U / U_{0}$, the velocity; $t=\left(T-T_{\infty}\right) /\left(T_{0}-T_{\infty}\right)$ the temperature; $f=$ $\mathrm{F} /\left(\mathrm{\rho B}_{0} \mathrm{~S}_{0} U_{0}\right)$, the stretching force. The dimensionless parameters are:

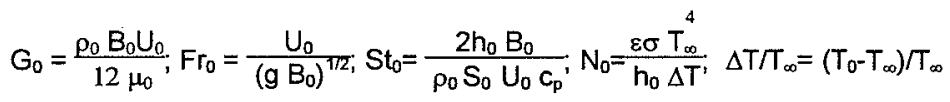

where: $\mathrm{Fr}$ is Freud number; $\mathrm{St}$ is Stanton number, $\mathrm{N}$ is a measure of the radiative to convective heat transfer; $G$ is a measure of the convective to tensile viscous force.

All symbols are collected in Appendix, in particular: the subscript " 0 " is referred at $x=0$, which coincides whit the die exit, neglecting die swelling phenomena; $T_{\infty}$ is the air temperature, which coincides with the ambient one. 
$\left(B_{0}, S_{0}\right)$, the temperature $\left(T_{0}\right)$ and the velocity $\left(U_{0}\right)$; the initial stretching force $\left(F_{0}\right)$, instead, will result from a shooting scheme such as to reproduce the roll velocity at the take up distance $\left(U_{L}\right)$.

\section{Experimental set-up}

Experimental testings were performed by a single screw laboratory extruder, with a rectangular die opening of $200 \times 0.25 \mathrm{~mm}^{2}$. Screw speed ranged between 40 and $80 \mathrm{rpm}$, thus allowing to obtain a volumetric flow rate of $0.23 \mathrm{~cm}^{3} / \mathrm{s}$ and $0.46 \mathrm{~cm}^{3} / \mathrm{s}$, respectively. The take up system was a three rolls calender, kept at constant temperature by water circulating at $60^{\circ} \mathrm{C}$. The calender was mounted on a moving carriage allowing to change the take up distance from 50 to $150 \mathrm{~mm}$. The rolls peripheral velocity ranged between 3 to $23.5 \mathrm{~m} / \mathrm{min}$. The die temperature was set depending on the processed polymer: $220^{\circ} \mathrm{C}$ for $\mathrm{PP}$ and $280^{\circ} \mathrm{C}$ for PET.

Surface temperature detection was carried out by means of an Agema 870 system, with a thermal typical sensitivity of about $0.1^{\circ} \mathrm{C}$ at room temperature and of spatial resolution of 1.5 $\mathrm{mm}^{2}$ per pixel at the operating conditions.

Due to the low value of polymer film thickness, the film cannot be treated as an opaque body: the radiometric analysis is more complicated needing a further information, i.e. the monocromatic normal emittance or transmittance at the sensor wavelength; this last was measured, for each testing condition, by means of preliminary tests: a slab at uniform high temperature was first placed in front of the camera and then with the film interposed; the ratio of the energy radiated in the two configurations gave the transmittance map of the film. Materials such as PET and PP exhibit a typical normal reflectance of 0.03 throughout the infrared spectral region [9]; thus, measuring the transmittance, the emittance can be derived. However it has to be remembered that the energy transmitted, at the sensor wavelength, through the film is negligible with respect to the one emitted, because the radiative surrounding temperature, i.e. the ambient temperature is low compared to the high temperature of the film (e.g. if $T_{\text {film }}=250^{\circ} \mathrm{C}, T_{\mathrm{amb}}=30^{\circ} \mathrm{C}$ and $\tau=0.5$, the emitted to transmitted energy ratio is about 500 ).

Data reduction takes place by means of a suitable code, which first allows to process thermal images, extracting both the longitudinal and the transverse temperature profiles; then it calculates the corresponding analytical profiles and compares them with the experimental ones.

\section{Results and discussion}

Figures 2 and 3 report both the temperature maps and the normalized temperature profiles along the longitudinal spatial variable for different sets of initial conditions: die opening geometry, material outlet speed, take-up distance and speed, temperature.

By looking at the pictures, it is important to note that the temperature field can be divided in three regions: the core region, in which the profiles are quite flat, i.e. the temperature is independent of the transverse coordinate; the edge region, in which the temperature field develops as a temperature boundary layer type; the edge surface being quickly cooled, faster than the inner one; a third region arise to merge smoothly the other one; in particular the temperature field derived from the actual model is the mean or the bulk temperature across the section, in fact it depends only on the longitudinal spatial variable, and so it has to be compared with the experimental one in the core region. The described thermal behaviour may be explained because of the presence of edge beads [10] especially in PET films. The evidence of the three regions is more marked in the PET extrusions.

For both PET and PP, the film width increases with decreasing "draw ratio" : this effect is enhanced with decreasing take-up distance and is more marked for PET films; the rheological properties have surely an effect on material behaviour. 
Temperature profiles confirm that, in our testing conditions, there is no experimental evidence about incoming crystallization, whose effect should be revealed by a change in the polymer properties and so in the slope of the profiles shown; probably, some crystallization effects are observable in the case of PP with higher take-up distance and lower velocity, here the available time being greater.

The film response for different take up speeds, in terms of dimensionless temperature, is practically the same both for PET and PP. The normalized temperature decay is contained within $50 \%$ for a take-up distance of $5 \mathrm{~cm}$, while it is about $70 \%$ at $15 \mathrm{~cm}$; this strong decay is one reason why industrial processes take place at low take-up distance.

As expected, the conductive contributions are negligible, in fact the influence of the cool roll is not evident in the film, even for lower take-up distances.

The simple mathematical model adopted, seems to describe quite well the polymers behaviour: the agreement between experimental and simulated data is better close to the die exit: in fact, in that region temperature profiles are quite flat, according to the mathematical model. Further development of this work will be devoted to evidence "dynamic" crystallization effect and to a better modelling, in order to take in to account the transverse variation of velocity and temperature profiles.

\section{APPENDIX}

The polymer viscosity, density and heat capacitance depend on temperature as follows:

$m=A_{1} \exp \left(B_{1} / T\right)$

$$
c_{p}[c a l /(g K)]=A_{2}+B_{2} t \quad r\left[g / \mathrm{cm}^{3}\right]=A_{3}-B_{3} t
$$

where $\mathrm{T}$ is in $\mathrm{K}$ and $\mathrm{t}$ is in ${ }^{\circ} \mathrm{C}$; the constants are:

$\begin{array}{lllllll} & \mathrm{A}_{1} & \mathrm{~A}_{2} & \mathrm{~A}_{3} & \mathrm{~B}_{1} & \mathrm{~B}_{2} & \mathrm{~B}_{3} \\ \text { PET } & 2.56 & 0.3 & 1.356 & 3869 & 0.00056 & 0.0005 \\ P P & 0.783 & 0.497 & 0.943 & 4476 & 0.0006 & 0.0007\end{array}$

\section{REFERENCES}

[1]AGASSANT (J.F.) et al. - Polymer processing. Hanser publ., 1991

[2] RAUWENDAAL (C.). - Polymer extrusion. Hanser publ., 1986

[3] BARQ (P.) et al. - Isothermal and anisothermal models for cast film extrusion. Int. Polymer Processing, $n^{\circ} 14,1992$

[4] PEARSON (J.) and RICHARDSON (S. M.). - Computational analysis of polymer processing. Appled science pubs., 1987

[5] D'HALEWYU (S.) et al. - Numerical simulation of the cast film process. Polymer Engineering and science, Vol.30, 1990

[6] CHARLES (L.) et al. - Computer modelling for polymer processing. Hanser publ.,1989

[7]AMMIRATI (C.C.) et al. - Heat exchange in film casting: modelling and experimental determination. PPS -12, Sorrento, 1996

[8] GASSANT (J. F.) et al. - Polymer processing, principles and modelling. Hanser publ.,1991

[9] DEWITT (D.P.) and NUTTER (G. D.). - Theory \& practice of radiation thermometry. Wiley \& sons, 1989

[10] DOBROTH (T.) and ERWIN (L.). - Causes of edge beads in cast films. Polymer Engineering and science, Vol. 6, 1986 
[9] DEWITT (D.P.) and NUTTER (G. D.). - Theory \& practice of radiation thermometry. Wiley \& sons, 1989

[10] DOBROTH (T.) and ERWIN (L.). - Causes of edge beads in cast films. Polymer Engineering and science, Vol.26, 1986

\section{NOTATIONS}

B film width

$c_{p} \quad$ specific heat

$F \quad$ drawing force

g gravitational acceleration

h heat transfer coefficient

p hydrostatic pressure

$S \quad$ film thickness

$\mathrm{T}$ temperature field

$\mathrm{U}$ velocity component in the $\mathrm{x}$-direction $\delta_{i, j} \quad$ Kronecker delta

$\varepsilon \quad$ surface emissivity

$\varepsilon \quad$ components of the strain tensor

$\mu \quad$ viscosity

$\rho$ density

$\sigma \quad$ Stefan Boltzmann constant

$\sigma_{i, j} \quad$ components of the stress tensor

Both lower case letters and the superscript "«" refer to dimensionless parameters.

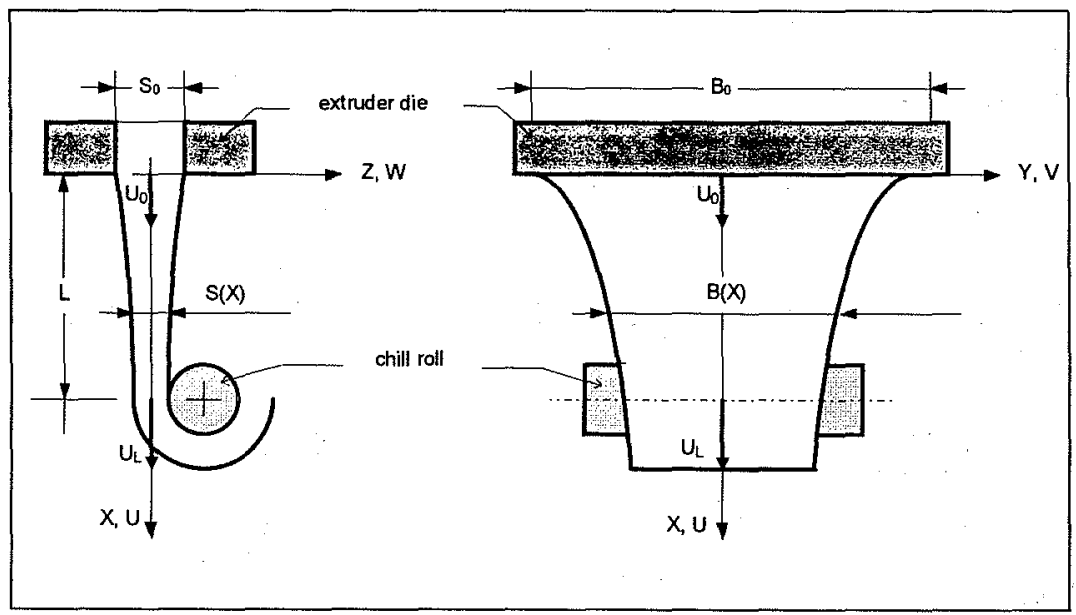

fig. 1 - sketch of cast film extrusion 


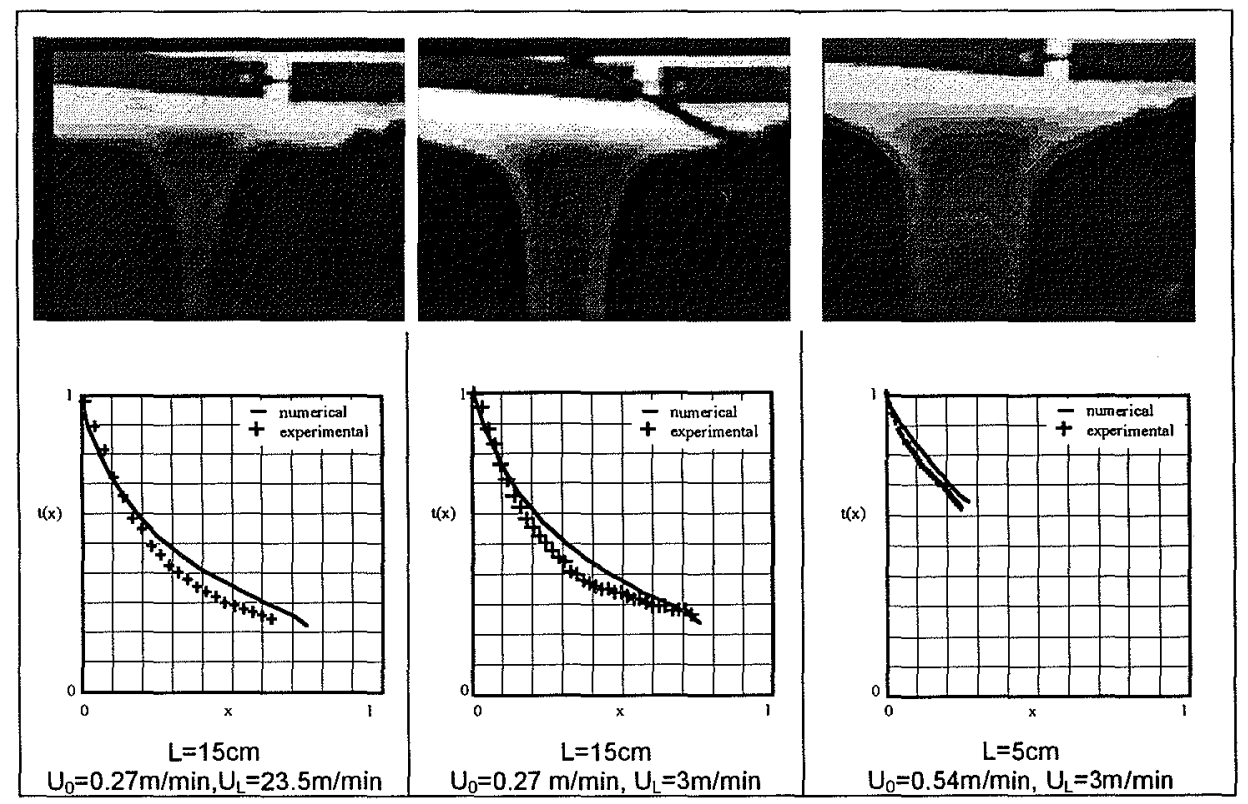

fig. $2 a-b-c-P E T$ with $B_{0}=200 \mathrm{~mm}, S_{0}=0.25 \mathrm{~mm}, T_{0}=280^{\circ} \mathrm{C}$
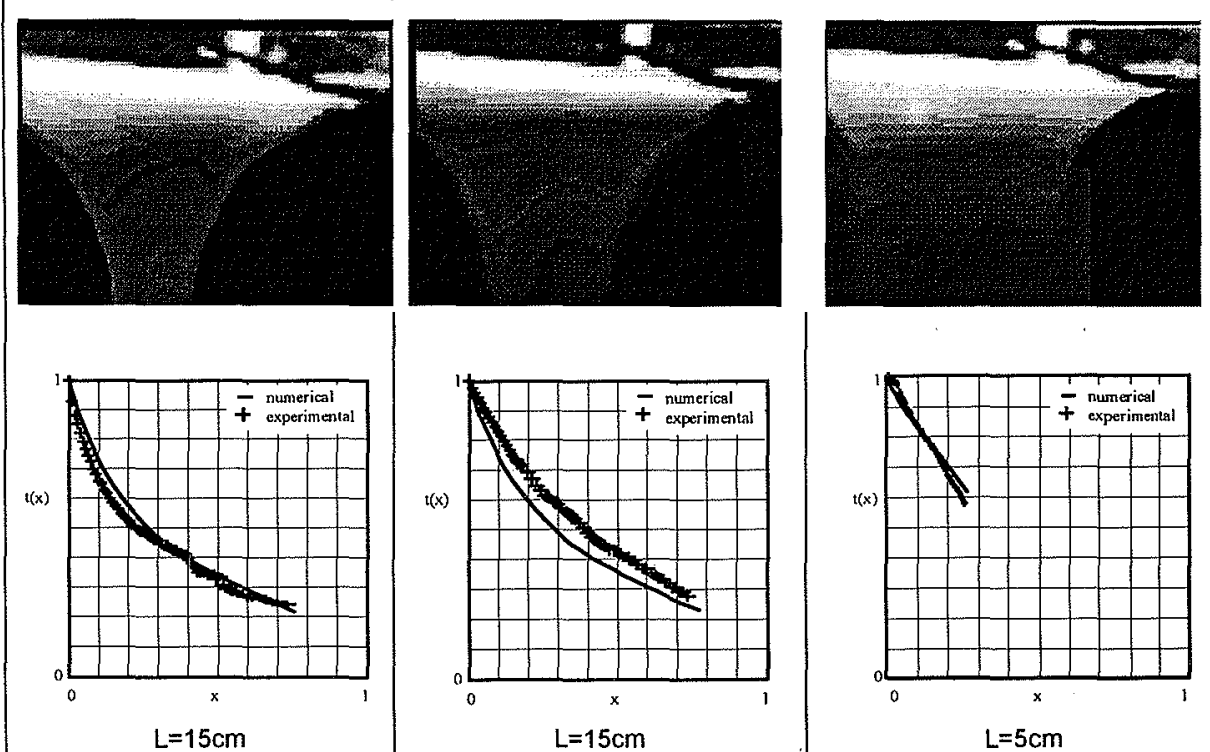

$\mathrm{U}_{0}=0.27 \mathrm{~m} / \mathrm{min}, \mathrm{U}_{\mathrm{L}}=23.5 \mathrm{~m} / \mathrm{min}$

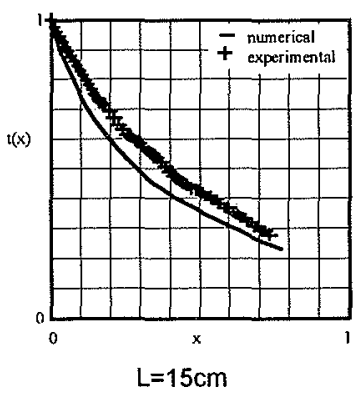

$\mathrm{U}_{0}=0.27 \mathrm{~m} / \mathrm{min}, \mathrm{U}_{\mathrm{L}}=3 \mathrm{~m} / \mathrm{min}$

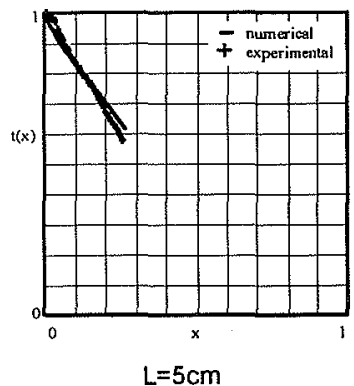

$\mathrm{U}_{0}=0.54 \mathrm{~m} / \mathrm{min}, \mathrm{U}_{\mathrm{L}}=3 \mathrm{~m} / \mathrm{min}$

fig. $3 a-b-c$ - PP with $B_{0}=200 \mathrm{~mm}, S_{0}=0.25 \mathrm{~mm}, T_{0}=220^{\circ} \mathrm{C}$ 